\title{
Testing Vertical Wind Shear and Nonlinear MJO-ENSO Interactions as Predictors for Subseasonal Atlantic Tropical Cyclone Forecasts
}

\author{
Kurt A. Hansen, ${ }^{\text {a }}$ Sharanya J. MAJumdar, ${ }^{a}$ Ben P. Kirtman, ${ }^{a}$ And Matthew A. JAniga ${ }^{\mathrm{b}}$ \\ ${ }^{\text {a }}$ Department of Atmospheric Sciences, Rosenstiel School of Marine and Atmospheric Science, Miami, Florida \\ ${ }^{\mathrm{b}}$ Marine Meteorology Division, Naval Research Laboratory, Monterey, California
}

(Manuscript received 1 July 2021, in final form 20 October 2021)

\begin{abstract}
Hansen et al. found patterns of vertical wind shear, relative humidity (RH), and nonlinear interactions between the Madden-Julian oscillation and El Niño-Southern Oscillation that impact subseasonal Atlantic TC activity. We test whether these patterns can be used to improve subseasonal predictions. To do this we build a statistical-dynamical hybrid model using Navy-ESPC reforecasts as a part of the SUBX project. By adding and removing Navy-ESPC reforecasted values of predictors from a logistic regression model, we assess the contribution of skill from each predictor. We find that Atlantic SSTs and the MJO are the most important factors governing subseasonal Atlantic TC activity. RH contributes little to subseasonal TC predictions; however, shear predictors improve forecast skill at 5-10-day lead times, before forecast shear errors become too large. Nonlinear MJO-ENSO interactions did not improve skill compared to separate linear considerations of these factors but did improve the reliability of predictions for high-probability active TC periods. Both nonlinear MJO-ENSO interactions and the subseasonal shear signal appear linked to PV streamer activity. This study suggests that correcting model shear biases and improving representation of Rossby wave breaking is the most efficient way to improve subseasonal Atlantic TC forecasts.
\end{abstract}

KEYWORDS: El Nino; Madden-Julian oscillation; Wind shear; Tropical cyclones; Statistical forecasting; Intraseasonal variability; Subseasonal variability

\section{Introduction}

\section{a. The subseasonal TC prediction problem}

Subseasonal time scales focus on timeframes between approximately 10 days and 6 weeks. Subseasonal forecasts of tropical cyclones (TCs) are of particular interest because these storms have considerable subseasonal variability and are high impact events. Although subseasonal forecasts have many potential uses, making predictions on these time scales has been challenging, leading some scientists to call the subseasonal range the "predictability desert" (Vitart et al. 2012).

This study aims to improve subseasonal Atlantic TC forecasts. The Atlantic is a particularly difficult basin for subseasonal forecasts for a variety of reasons (Lee et al. 2020a). The Atlantic is a marginal basin for TC genesis meaning predictions of TC activity are especially sensitive to model biases (Camargo 2013). Atlantic storms tend to form from African easterly waves (AEWs; Russell et al. 2017) that models resolve poorly (Camargo 2013). The Madden-Julian oscillation (MJO) (see section 1c) is one of the main sources of subseasonal predictability and does influence Atlantic TC activity through vertical wind shear. However, the MJO is primarily active in the Indian and Pacific Oceans and as a result these basins and downstream regions have more predictable environments while the Atlantic sees comparatively little benefit (Janiga et al. 2018). For these reasons it is important to explore other potential sources of predictability when considering subseasonal Atlantic TC forecasts.

Corresponding author: Kurt A. Hansen, kurt.hansen@rsmas. miami.edu
Previous studies have mainly relied on the MJO, El Niño-Southern Oscillation (ENSO), and dynamical model forecasts of TCs, to produce skillful subseasonal TC forecasts in the Atlantic and other basins (Leroy and Wheeler 2008; Vitart et al. 2010; Klotzbach 2007; Lee et al. 2018; Camp et al. 2018; Belanger et al. 2010; Elsberry et al. 2010; Lee et al. 2020a). Leroy and Wheeler (2008) made statistical predictions of TC genesis in the Southern Hemisphere using the MJO, ENSO, and Indian Ocean sea surface temperatures (SSTs). They produced skillful subseasonal predictions primarily due to the contribution of the MJO [from their Fig. 15, approximately $90 \%$ of the Brier skill score (BSS) of their total selection was achieved using solely the MJO]. Henderson and Maloney (2013) made statistical subseasonal predictions of TC genesis in the Atlantic using a similar technique. While predictions were still skillful, they showed less skill than in Leroy and Wheeler (2008) and only marginally better than daily climatology. The MJO was found to have much less contribution to their statistical model, and Atlantic SSTs were found to be the most important predictor. Dynamical models generally produce more accurate forecasts but only for short lead times. Lee et al. (2018) investigated subseasonal predictions of TC occurrence using TC tracks produced by dynamical models in the S2S dataset. Initially, forecast skill in the Atlantic was very high (BSS $>0.5$, see section $2 \mathrm{f}$ for skill scores), but nearly all models lost skill by week 2 . However, Vitart et al. (2010) was able to produce dynamical forecasts that were more skillful at predicting TC occurrence in the Southern Hemisphere than statistical forecasts at week 3 after implementing a model bias correction (BSS $>0.08$ ). Statistical-dynamical models like that used in Qian et al. (2020) can provide skill greater than both statistical and dynamical 
models individually. While these studies demonstrate skillful subseasonal prediction, they rely mainly on the same few predictors and overlook several sources of predictability.

\section{b. Predictors: Environmental conditions}

Shear acts to disrupt the organization of TCs (DeMaria 1996), and low RH can hinder vertical development in TCs (Gray 1979). While shear and RH are often used in analyzing and predicting hurricanes on weather scales, they are largely overlooked as predictors for subseasonal forecasts. However, the subseasonal scientific community is beginning to use environmental conditions as predictors, instead of just viewing them as mechanisms. Operational subseasonal forecasts from Colorado State University use shear forecasts from several climate models as input for its predictions. Shear and $\mathrm{RH}$ are chosen as subseasonal environmental predictors in this study based on the findings of Hansen et al. (2020, hereafter H20) that showed that these parameters are associated with subseasonal TC activity in the Atlantic. This study is the first to assess the utility of forecasted regional environmental conditions for use in subseasonal TC prediction. While we also include MJO and ENSO as predictors which influence these environmental parameters, we expect shear and $\mathrm{RH}$ will have a more direct connection to TC activity and represent the aggregate influence of several phenomena and thus have the potential to contribute to predictability, especially at earlier lead times.

\section{c. MJO and ENSO}

Another potential source of predictability is nonlinear interactions between the MJO and ENSO. The MJO is a continent-scale region of convection that slowly propagates around the globe over the course of 40-90 days or at about $5 \mathrm{~m} \mathrm{~s}^{-1}$ (Jones et al. 2004; Kim et al. 2018; Knutson et al. 1986). Its large scale drives an atmospheric circulation that influences weather globally, and its slow motion provides subseasonal predictability (Zhang 2005). In this study we find enhanced Atlantic TC activity occurs during MJO phases 8 and 1 similar to Kiladis et al. (2014).

ENSO is a pattern of sea surface temperatures (SSTs) in the tropical east Pacific that varies over the span of 2-7 years. The warm phase of ENSO (El Niño) is generally associated with higher shear and suppressed Atlantic hurricane activity on seasonal scales and the cool phase (La Niña) sees lighter shear and more Atlantic TC activity (Gray 1984).

Several studies have shown that the influence of the MJO on subseasonal TC activity is modulated by ENSO phase (H20; Klotzbach and Oliver 2015). Variability of TC activity with MJO phase is larger during La Niñas (H20). Strong La Niñas can also cause a shift in favorable MJO phase (H20). Linear statistical models do not consider these nonlinear interactions. While dynamical models may be capable of simulating the nonlinear MJO/ENSO interaction, given the difficulty that dynamical models have representing the MJO, they are likely not capturing this interaction correctly. These shortcomings provide an opportunity to improve forecasts. This study is the first to assess the utility of nonlinear MJO/ENSO interaction for use in subseasonal TC prediction.

\section{d. Hypothesis}

To assess the contribution of skill from these sources of predictability, we utilize statistical-dynamical hybrid models. The statistical base we use for the models are multiple linear regression and logistic regression. The dynamical inputs to the statistical models come from the Navy Earth System Prediction Capability (Navy-ESPC) hindcasts (Carman et al. 2017). The predictors we are assessing in this study are two shear parameters, two variants of an RH parameter, main development region (MDR) SSTs, two measures of ENSO, and the MJO principal components (PCs). We also create an $\mathrm{MJO}$ phase predictor and a nonlinear $\mathrm{MJO} / \mathrm{ENSO}$ predictor. By adding and removing predictors from the statisticaldynamical hybrid model and comparing skill we can assess which sources of predictability are most useful and for what lead times. We hypothesize that by including nonlinear MJO/ENSO interactions and forecasts of shear and $\mathrm{RH}$ in a statistical-dynamical hybrid model, we can improve upon our benchmark model (MJO, ENSO, and MDR SSTs). We hope that by demonstrating the predictive utility of regional environmental parameters and nonlinear MJO/ENSO interactions, we will not need to depend on a model's ability to accurately represent complex TC mechanics to gain subseasonal skill. Data and methods are described in section 2, analysis of the statistical-dynamical hybrid model is described in section 3, physical mechanisms associated with predictors are discussed in section 4 , and the summary and discussion are provided in section 5 .

\section{Data and methods}

\section{a. TC data}

The 6-hourly TC data from the National Hurricane Center best track database (HURDAT2, Landsea and Franklin 2013) are retrieved from the International Best Track Archive for Climate Stewardship (IBTrACS; Knapp et al. 2010). TC activity is quantified using accumulated cyclone energy (ACE), defined as the summation of the square of the maximum sustained surface winds (in knots; $1 \mathrm{kt} \approx 0.51 \mathrm{~m} \mathrm{~s}^{-1}$ ) for a TC at each 6-h interval. For this study, ACE is calculated for purely tropical TCs with maximum sustained winds exceeding $34 \mathrm{kt}$ in the North Atlantic south of $30^{\circ} \mathrm{N}$ during August-September-October (ASO). We select ACE because of its utility as a continuous function and its added weight toward more intense and likely impactful TCs. The TC metric used to calibrate and verify forecasts is a normalized anomaly of the 5-day running mean of ACE or $\mathrm{ACE}_{5}^{\prime}$. This is done to smooth over weather scales and remove the seasonal cycle, although this will still capture interseasonal variability.

\section{b. Reanalysis data}

RH, shear, SST, and potential vorticity (PV) fields are calculated or taken directly from the ERA5 database (Hersbach et al. 2020). Hourly data are available at 137 vertical levels on 
a $0.25^{\circ}$ grid, although for this study only 0000 UTC data at four vertical levels and $0.75^{\circ}$ horizontal resolution are used for faster computation. Reanalysis data during ASO periods from 1979 to 2019 are used in this study. The 200- and $850-\mathrm{hPa}$ total winds are used for analysis of shear, the 700$\mathrm{hPa}$ level is used for $\mathrm{RH}(600 \mathrm{hPa}$ was also tested but found not to be different from $700 \mathrm{hPa}$ ). $\mathrm{PV}$ is taken from the 200$\mathrm{hPa}$ level for use in later analysis of physical mechanisms behind the shear pattern. SST data were used in calculating ENSO and MDR SST.

The oceanic Niño index from the NOAA/NCEP Climate Prediction Center was used for comparison although we found it does not have a significant impact on results.

\section{c. Navy-ESPC}

The Navy-ESPC is a fully coupled Earth system model with atmosphere, land, ocean and ice components (Barton et al. 2021). The grid interval of the atmospheric model in Navy ESPC is about $37 \mathrm{~km}$ with 60 vertical levels which is sufficient for the generation of TCs (Moon et al. 2020). From 1999 to 2015, 45-day reforecasts were initialized four times a week for the Subseasonal Experiment (SubX) (Pegion et al. 2019) yielding 589 forecasts. For the period of 2009-15, atmospheric initial conditions were taken from a consistent analysis dataset generated using Navy-ESPC while prior years were initialized using operational NOGAPS analyses. For this study we only considered the first 30 days of the forecasts and only for forecasts initialized during August and September to ensure that verification occurs during ASO. Reforecast data provided values of RH, shear and the two principal components (PCs) of the MJO (see section 2e). Navy-ESPC forecasted anomalies of $\mathrm{RH}$ and shear were calculated relative to the model lead time i.e., the anomalies for an 10 August forecast initialized on 5 August would be relative to the average of all 1999-2015 ASO reforecasts at 5-day lead times. This removes model bias but does not remove the seasonal cycle. In the short window of the peak hurricane season, the typical shear anomalies do not change much compared with the model bias, and the small sample of years means that a climatology calculated relative to model lead time and seasonal climatology would be highly variable.

\section{d. SSTs and ENSO}

Several predictors are created using the persistence of SSTs: the Niño-3.4 region $\left(5^{\circ} \mathrm{S}-5^{\circ} \mathrm{N}, 120^{\circ}-170^{\circ} \mathrm{W}\right)$, Niño- $1+2$ region $\left(0^{\circ}-10^{\circ} \mathrm{S}, 90^{\circ}-80^{\circ} \mathrm{W}\right)$, and $\operatorname{MDR}\left(7.5^{\circ}-22.5^{\circ} \mathrm{N}, 40^{\circ}-75^{\circ} \mathrm{W}\right)$. SST anomalies are averaged over the first 5 days of the forecast period over each region in order to create single value persistence forecasts.

\section{e. $M J O$}

For this study we quantify the MJO using outgoing longwave radiation (OLR) which serves as a proxy for convective activity. For reforecasts the MJO measured using the realtime OLR MJO index (ROMI) which uses the PCs found by Kiladis et al. (2014). From the PCs the MJO can be classified as one of eight phases or in a neutral/inactive state if the MJO is below a 0.7 magnitude threshold. This threshold is lower than the 1.0 threshold previous studies but still captures the MJO connection to Atlantic TC activity and allows for a more robust sampling of nonlinear $\mathrm{MJO} / \mathrm{ENSO}$ connections. Both the PCs and the phase of the MJO are assessed as predictors. To calculate the nonlinear MJO/ENSO predictor, historic OMI values are used (Kiladis et al. 2014). The MJO is separated into nine bins, each MJO phase and inactive MJO (again using the 0.7 threshold). ENSO is separated into eight bins with an exclusive range of $0.5^{\circ} \mathrm{C}$ with events greater than $2.0^{\circ} \mathrm{C}$ magnitude being included in the highest and lowest bins. Average $\mathrm{ACE}_{5}^{\prime}$ anomalies are calculated for each combined MJO/ENSO bin from the 1979 to 2020 ASO periods giving a $9 \times 8$ array of expected $\mathrm{ACE}_{5}^{\prime}$ anomalies for each $\mathrm{MJO}$ and ENSO phase. To create the nonlinear MJO/ENSO forecast the MJO phase is taken from the Navy-ESPC forecast and ENSO is taken from a persistence forecast and are used to find a corresponding value of average $\mathrm{ACE}_{5}^{\prime}$ from the $9 \times 8$ array. The $9 \times 8$ array is recalculated with out of year samples for each prediction to avoid overfitting to the observed values. The MJO ACE predictor is calculated similarly but only uses nine bins representing the MJO phases.

\section{f. Removing ENSO and seasonal signals}

To find subseasonal patterns in environmental fields that indicate enhanced subseasonal TC activity we use the compositing method ACE by year (ABY) from H20. ABY was shown to highlight patterns associated with the MJO and other subseasonal factors while removing signals from ENSO. The selection of periods to go into an ABY composite is done by taking the top $33 \%$ of $\mathrm{ACE}_{5}^{\prime}$ events from each year. The running mean of ACE smooths out weather signals, and the normalized anomaly removes the seasonal cycle. Equal selection of periods from each year ensures that oscillations that impact Atlantic hurricane activity on seasonal scales, such as ENSO, are averaged out. Composites of shear and $\mathrm{RH}$ are taken during these top $\mathrm{ACE}_{5}^{\prime}$ events producing an environmental pattern that is associated with simultaneous subseasonally active TC periods.

These ABY composites are used to select predictors based on area-average anomalies over important regions. In this study we choose two shear parameters and one RH parameter (see section 3a). In $\mathrm{H} 20$ and for the ABY composites of shear in this study, environmental conditions within $8^{\circ}$ latitude/longitude of a TC center are removed from the ABY composites, but for the ABY composite of RH we include TCs. NavyESPC hindcasts are used to calculate predicted values of each parameter and used as input for the statistical models.

\section{g. Statistical models}

A least squares linear regression model is used to create a forecast of $\mathrm{ACE}_{5}^{\prime}$ for 5-, 10-, 15-, 20-, 25-, and 30-day forecasts. The multiple linear regression is trained using persistence forecasts of SST parameters and Navy-ESPC forecasts of shear/RH parameters and MJO as predictors, and $\mathrm{ACE}_{5}^{\prime}$ (from IBTrACs) as the predictand. Training data for the linear model exclude data from the year of the forecast to avoid 
overfitting of the model. A linear regression model allows us to analyze the contribution of each predictor to the model at each forecast lead time. To create probabilistic forecasts, we use a logistic regression model. The logistic regression model is trained using the same predictor dataset and cross validation method as the linear regression model. Logistic forecasts are verified against the binary value of above average or below average $\mathrm{ACE}_{5}^{\prime}$. Both statistical methods are run using the statsmodel Python module. The logistic regression model uses the liblinear solver.

\section{h. Verification metrics}

To evaluate the model skill, we primarily use BSS (Wilks 2011). BSS values greater than 0 indicate skillful forecasts. BSS is based on the Brier score (BS), defined as follows:

$$
\mathrm{BS}=\frac{1}{N} \sum_{t=1}^{N}\left(f_{t}-o_{t}\right)^{2},
$$

where $N$ is the number of forecasts, $f_{t}$ is the individual forecast probability of an event, and $o_{t}$ is the observed outcome ( 0 or 1$)$ of events. BSS is defined as follows:

$$
\mathrm{BSS}=1-\frac{\mathrm{BS}}{\mathrm{BS}_{\mathrm{Ref}}},
$$

where $\mathrm{BS}$ is the skill of the model and $\mathrm{BS}_{\mathrm{Ref}}$ is the reference skill. In this study $\mathrm{BS}_{\mathrm{Ref}}$ is based on a constant forecast of the ASO climatological odds of experiencing an above average $\mathrm{ACE}_{5}^{\prime}$ period (roughly 0.3$)^{1}$

We use reliability diagrams and histograms following Hsu and Murphy (1986). Reliability diagrams compare the forecasted probability of an event with the observed percent frequency of an event within a forecast probability range. In this study we use $5 \%$ bins. A perfectly reliable model would have a one to one ratio of forecasted chances of an event with the observed frequency of the event.

We also utilize receiver operating characteristic (ROC), hit and false alarm values for forecasts of likely (50\%) active periods. Hits indicate times the model correctly predicted an active period, and false alarms indicate incorrect predictions of an active period.

Statistical testing uses a two-tailed two-sample Student's $t$ test and is evaluated at the $95 \%$ level.

\section{Results}

\section{a. Environmental parameters}

For this study, three parameters are selected to represent a favorable environment for active subseasonally active periods of TC activity. These are based on ABY composites of shear and RH. The pattern of shear associated with subseasonal TC activity (Fig. 1a) is marked by a dipole pattern of negative

\footnotetext{
${ }^{1}$ Because TCs are rare events, there is a non-normal distribution of TC activity and the odds of any given period being above average is less than $50 \%$.
}

anomalies in the Caribbean and positive anomalies to the north around the Bahamas and Bermuda. This is consistent with H20. As both the negative Caribbean shear anomalies and positive Bahamas shear anomalies appear important, each are made into a predictor. The Caribbean shear predictor is the negative of the average anomaly of 5-day running mean values of shear inside the region: $10^{\circ}-18^{\circ} \mathrm{N}, 60^{\circ}-80^{\circ} \mathrm{W}$. The Bahamas shear predictor is the average anomalies of 5-day running mean values of shear inside the region: $24^{\circ}-33^{\circ} \mathrm{N}, 60^{\circ}-80^{\circ} \mathrm{W}$.

In $\mathrm{H} 20$, RH had a weak signal in association with subseasonal TC activity. We find similarly weak signals of RH in ABY composites using the ERA5 database which suggests that $\mathrm{RH}$ will be a poor predictor. However, if TCs are not removed from the $\mathrm{ABY}$ composite than there is a strong positive $\mathrm{RH}$ anomaly in association with subseasonal TC activity (Fig. 1b). As TCs are not removed from the Navy-ESPC forecasts, we include an RH parameter by taking the average anomalies of 5 -day running mean values of $\mathrm{RH}$ over $15^{\circ}-25^{\circ} \mathrm{N}, 45^{\circ}-75^{\circ} \mathrm{W}$. Another RH parameter called RHv2 was created using a broader region: $10^{\circ}-30^{\circ} \mathrm{N}, 20^{\circ}-75^{\circ} \mathrm{W}$. Several variants of the shear and RH parameters were tested and showed little difference with the parameters defined above.

To test the Navy-ESPC's ability to reproduce the subseasonal shear signal we take ABY composites of Navy-ESPC forecast fields. ABY composites use observed $\mathrm{ACE}_{5}^{\prime}$ and are created for 5-, 10-, 15-, and 20-day forecasts shown in Fig. 2. At 5-day lead times the subseasonal signal of the dipole shear pattern is well represented by the model and is slightly stronger than the reanalysis ABY signal. At 10 days this signal is weaker, although still apparent. By 15 days the pattern begins to erode, although forecasted negative shear anomalies in the Caribbean are still seen in association with subseasonal TC activity. At 20-day lead times the subseasonal shear pattern is not represented. This preliminary check of the Navy-ESPC suggests that 10-day forecasts of shear should be useful in predicting TC activity. However, growing model errors limit the contribution of shear forecasts beyond 15 days.

\section{b. Linear correlations of predictors}

Table 1 shows the linear correlation between normalized values of the Navy-ESPC or persistence predictors and $\mathrm{ACE}_{5}^{\prime}$ at lead times of 5, 10, 15, 20, 25, and 30 days. Caution should be used when comparing potential skill of individual predictors as the relation between $\mathrm{ACE}_{5}^{\prime}$ and one predictor may be nonlinear or may be co-correlated with another predictor.

Both the Caribbean shear index and Bahamas shear index appear to have significant positive correlations with $\mathrm{ACE}_{5}^{\prime}$ for the first 10 days. This generally agrees with the analysis of Navy-ESPC ABY shear composites in Fig. 2 that showed a degradation of the subseasonal shear signal around 10-day lead times.

The predicted values of the RH parameter (RHv1) have a weak positive correlation with $\mathrm{ACE}_{5}^{\prime}$ through 10-day lead times. In $\mathrm{H} 20$, RH did not have a clear connection to TC 

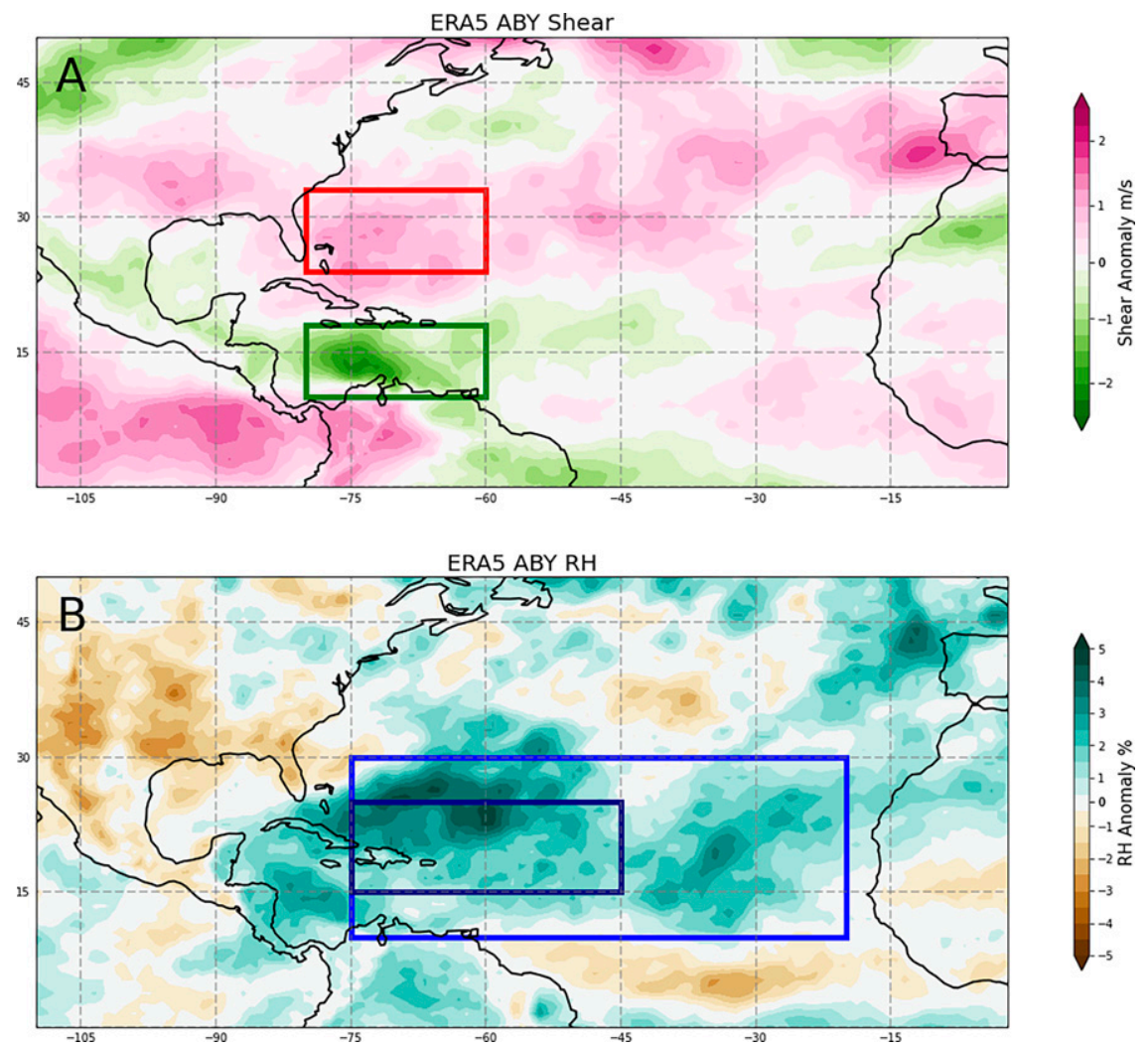

FIG. 1. ABY composites of the top third of subseasonal $\mathrm{ACE}_{5}^{\prime}$ events in the Atlantic during ASO 1979-2019 of ERA5 values of (a) 200-850-hPa shear. The green box highlights the region used for the Caribbean shear parameter and the red box indicates the region used for the Bahamas shear parameter. (b) ABY composite of 700-hPa RH. The dark blue box indicates the region used to calculate the RHv1 $(\mathrm{RH})$ parameter, and the light blue box indicates the region used for the RHv2 parameter.

activity through $\mathrm{ABY}$ composites, and we found the subseasonal RH signal came primarily from TCs. If the NavyESPC has problems with TC representation, we would expect $\mathrm{RH}$ to behave poorly as a predictor. While the basin-wide RH (RHv2) has marginally stronger correlations with $\mathrm{ACE}_{5}^{\prime}$ than RHv1, ultimately the statistical models produced higher skill with RHv1. Therefore, RHv2 will not be used in the rest of the study.
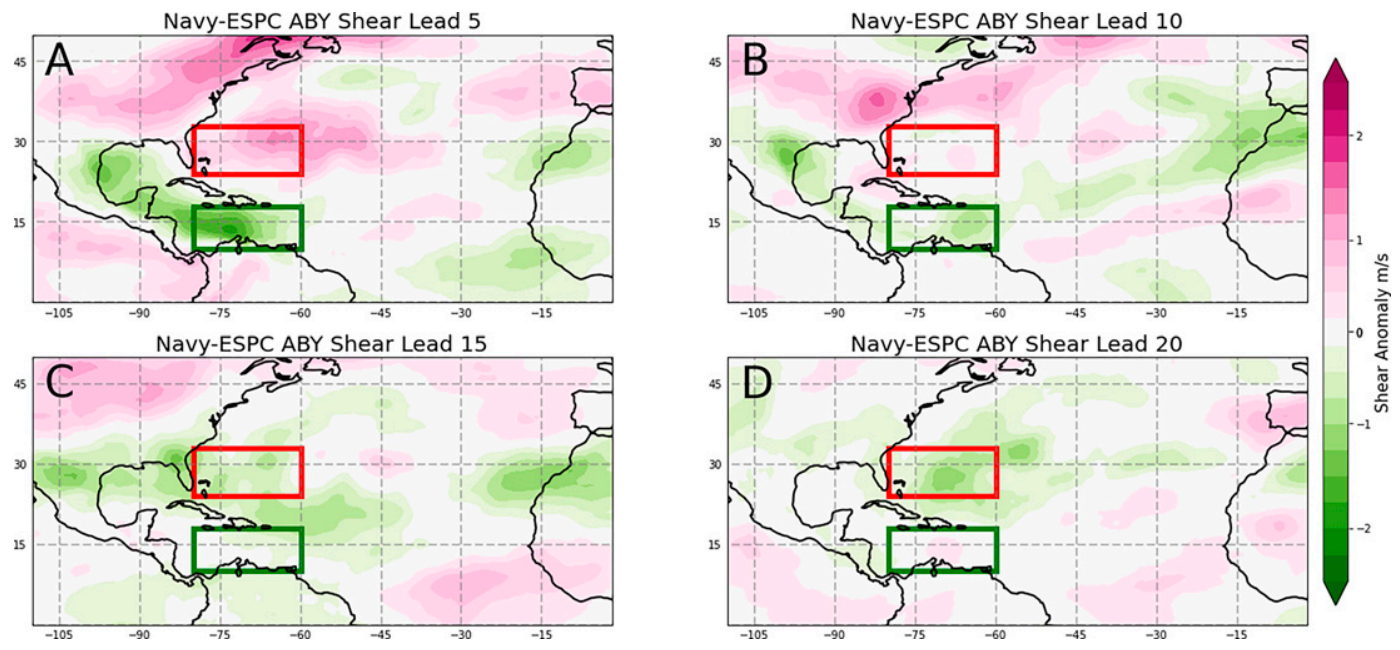

FIG. 2. Reproduction of ABY composites of 200-850-hPa shear using 1999-2016 Navy-ESPC reforecasts for (a) 5-, (b) 10-, (c) 15-, and (d) 20-day lead times. 
TABLE 1. Correlation of $\mathrm{ACE}_{5}^{\prime}$ with normalized values of various predictors at increasing lead times in days. RH and shear parameters constitute environmental predictors; PC1, PC2, and MJO ACE are MJO predictors; and MDR SST, Niño-3.4, and Niño$1+2$ are SST predictors. Environmental and MJO predictors are calculated from Navy-ESPC reforecasts while SST predictors use persistence forecasting. Boldface values are significantly different from 0 at the $95 \%$ level.

\begin{tabular}{|c|c|c|c|c|c|c|c|c|c|c|c|}
\hline Coefficients & $\begin{array}{c}\text { Bahamas } \\
\text { shear }\end{array}$ & $\begin{array}{c}\text { Caribbean } \\
\text { shear }\end{array}$ & RH & RHv2 & MJO PC1 & MJO PC2 & MJO ACE & NL MJO ENSO & Niño-3.4 & MDR & Niño-1+2 \\
\hline 5 & 0.29 & 0.32 & 0.04 & 0.09 & 0.11 & 0.15 & 0.22 & 0.22 & -0.04 & 0.09 & -0.13 \\
\hline 10 & 0.14 & 0.19 & 0.11 & 0.11 & 0.00 & 0.13 & 0.07 & 0.06 & -0.06 & 0.16 & -0.15 \\
\hline 15 & -0.07 & 0.01 & 0.04 & -0.06 & -0.01 & 0.13 & 0.05 & 0.09 & -0.10 & 0.18 & -0.17 \\
\hline 20 & -0.01 & 0.04 & 0.06 & 0.01 & 0.01 & 0.14 & 0.09 & 0.06 & -0.11 & 0.18 & -0.14 \\
\hline 25 & 0.03 & -0.02 & 0.03 & -0.01 & -0.06 & 0.09 & -0.05 & -0.04 & -0.12 & 0.21 & -0.18 \\
\hline 30 & 0.04 & 0.06 & 0.02 & -0.07 & -0.03 & 0.11 & 0.01 & 0.07 & -0.09 & 0.21 & -0.15 \\
\hline
\end{tabular}

The Navy-ESPC forecasted values of MJO PC2 has a consistent positive relation with $\mathrm{ACE}_{5}^{\prime}$ through 30 days. The forecasts of MJO PC1 only appears to have a significant correlation with $\mathrm{ACE}_{5}^{\prime}$ for the first five days.

In general SST predictors appear to have consistent correlations with $\mathrm{ACE}_{5}^{\prime}$ through the entire forecast period. The Niño-3.4 and Niño-1+2 regions have negative correlations with $\mathrm{ACE}_{5}^{\prime}$, and MDR SST has positive correlations.

The combined predictors, MJO ACE and nonlinear MJO_ENSO, use average out-of-sample $\mathrm{ACE}_{5}^{\prime}$ data within specified bins to create forecast values. This binning method and the relatively short climatology can create some small sample sizes from which the predictors are calculated. This leads to the combined predictors having less significant correlations than the components from which they were built (e.g., the PCs and Niño-3.4).

The forecasted MJO ACE predictor has positive correlations with $\mathrm{ACE}_{5}^{\prime}$ up to 20-day lead times. Unlike PC2 forecasts, the strength of the correlation decreases for increasing lead times. In this study we find phases 8 and 1 of ROMI are associated with the most TC activity in the Atlantic. Average $\mathrm{ACE}_{5}^{\prime}$ anomalies during all other phases are negative. The nonlinear $\mathrm{MJO} / \mathrm{ENSO}$ predictor also has positive correlations with $\mathrm{ACE}_{5}^{\prime}$ up to 20-day lead times.

\section{c. Multiple linear regression}

The use of a multiple linear regression (MLR) model allows for a more direct comparison of parameters by assessing their contribution to the model. Shown in Table 2, the most important factor in the MLR is MDR SST which is the strongest predictor in the model past 5-day lead times. This is in agreement with Henderson and Maloney (2013). The MJO PC2 also has a significant and consistent contribution to the model at all lead times. MJO PC1 has a significant contribution only at 5-day lead times. The Niño-3.4 region does not have a significant contribution to the model. However, the Niño-1+2 region does. In fact, the Niño-1+2 region is often the second most important predictor. If both ENSO metrics are included in the MLR model the Niño-3.4 parameter has a strong positive correlation with $\mathrm{ACE}_{5}^{\prime}$ (opposite of its established impact on seasonal TC activity) and Niño- $1+2$ has a stronger negative correlation. These two parameters would generally counteract each other as Niño- $1+2$ and Niño-3.4 are co- correlated. The reason Niño- $1+2$ has significant correlations, while Niño-3.4 does not, may be because the Niño- $1+2$ region is smaller and has a shallower mixed layer (de Boyer Montégut et al. 2004) and thus may exhibit more subseasonal variability. The Niño- $1+2$ region is also closer to the Atlantic so may have a more immediate influence on TC activity. The positive correlation of Niño-3.4 when Niño- $1+2$ is also included as a parameter may be due to the ENSO signal being primarily captured by Niño-1+2, and Niño-3.4 capturing the residual signal related to a central Pacific or Modoki El Niño.

RH, unsurprisingly, has almost no contribution to the MLR model. $\mathrm{RH}$ has little signal in ABY composites suggesting it is not an important environmental indicator of subseasonal TC variability. If Navy-ESPC representation of TCs is poor, we would expect the RH parameter to be insignificant.

The shear parameters are the largest contributors at 5 days and Caribbean shear has a significant contribution at 10 days. However, at days 15-25 the shear parameters' coefficients becomes negative, sometimes significantly so. This appears to be associated with model error. The ABY shear signals in Fig. 2 only capture the subseasonal signal clearly for the first 10-15 days. At 20-day lead times, the subseasonal shear signal in the Navy-ESPC is, if anything, reversed from the subseasonal shear signal in reanalysis which would explain the negative correlations. The MJO ACE predictor contributes more to the model than the individual MJO PCs at 5-day lead times and has a positive coefficient up to 20-day lead times. However, there is more uncertainty in the coefficients. While the MJO PCs have relatively stable contributions to the MLR with lead time (the coefficients are almost constant), the coefficients of MJO ACE inconsistently decrease. MJO/ENSO ACE coefficients are similar to MJO ACE both in value and inconsistency. The bins for MJO/ENSO ACE may be overly specific, relying on a small number of cases to make a prediction. Still, MJO/ENSO ACE has near significant positive correlations through 20-day lead times.

\section{d. Logistic regression}

In Table 3, we compare the logistic regression model skill for different predictive schemes. The parameters included for each model are shown in Table 4. A comparison of the Total, MJO_SST, and SST models demonstrates the range of predictability for each type of predictor. The inclusion of 


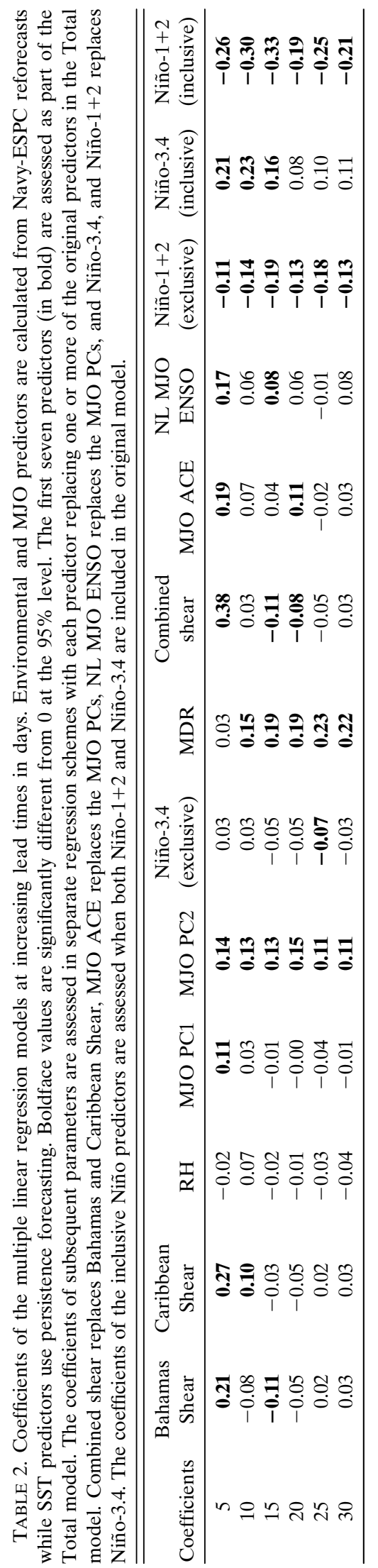

environmental parameters greatly improves the skill of $\mathrm{ACE}_{5}^{\prime}$ forecasts using the Total model at 5-day lead times. This benefit also exists at 10-day lead times although it is much smaller. From 15- to 20-day lead times the best predictions are made with a combination of the MJO PCs and SST predictors, although these forecasts only marginally outperform the Total suite of predictions and the SST only predictions. At lead times past 25 days, the skill from the MJO components has diminished, and only the SST predictors appear to contribute skill. This is in agreement with our understanding of predictability. Environmental conditions primarily have predictability on weather scales, perhaps extended into the subseasonal range through regional averages. The MJO has predictability for much longer periods and thus contributes to skill in the subseasonal range. Skill at lead times around one month is very low and almost entirely attributable to persistence of SSTs.

Replacing the MJO and ENSO parameters with the nonlinear MJO_ENSO ACE predictor (see section 2e) to make the NL Total model appears to slightly improve the forecast skill at 5 days. However, at all other lead times the skill is nearly the same as the Total model or slightly lower. In a similar fashion, using MJO ACE in place of the MJO PCs in the Total MJO ACE model may slightly improve day-5 forecasts but produces similar or lower values of BSS at all other lead times. It appears this method of combining parameters to account for nonlinear interactions does not have a significant impact on skill. The nonlinear MJO/ENSO term does not appear useful for subseasonal forecasting with the possible exception during very strong La Niñas and, even here, a more robust climatology is needed to be sure of these results.

While the Niño-1+2 index has more robust correlations with $\mathrm{ACE}_{5}^{\prime}$ than the Niño-3.4 index, replacing the Niño-3.4 index with Niño-1+2 did not appear to change the skill meaningfully. Niño- $1+2$ did slightly improve forecasts at lead times around 15 days but performed worse at longer lead times when SST predictors were most useful, likely because of the higher variability of SSTs due to a shallower mixed layer.

Removing $\mathrm{RH}$ from the Total model in general acts to improve skill. However, this improvement is rather small. This improvement is consistent when removing $\mathrm{RH}$ from the Total MJO ACE (not shown) and Total MJO_ENSO ACE. This is hardly surprising as RH has little ABY signal and low correlations with $\mathrm{ACE}_{5}^{\prime}$.

\section{e. Reliability}

Figures 3 and 4 show reliability diagrams for the Total(-RH) model and NL Total(-RH) model at 5-20-day lead times, as these were some of the best performing models for early lead times and have been particularly insightful. In general, the reliability diagrams show that as our forecasted odds of an active period increased, the observed frequency of active periods increased regardless of the predictors included in the model and for most lead times. At 5-day lead times of the Total(-RH) model and for near climatological forecasts, the reliability curve nearly follows the perfect one-to-one ratio. However, the reliability of high probability forecasts $(>60 \%)$ produced by the 
TABLE 3. Brier skill score of $\mathrm{ACE}_{5}^{\prime}$ forecasts using the logistic regression model forecast schemes at increasing lead times in days. The average daily climatology or zero $\mathrm{ACE}_{5}^{\prime}$ is used as the baseline prediction. Bolded values indicate that the model is the best performing or competitive with the best performing model for that lead time.

\begin{tabular}{|c|c|c|c|c|c|c|c|c|}
\hline BSS & Total & MJO_SST & SST & NL Total & Total(-RH) & NL Total(-RH) & Total MJO ACE & Total replace Niño- $1+2$ \\
\hline 5 & 0.10 & 0.02 & -0.01 & 0.11 & 0.10 & 0.11 & $\mathbf{0 . 1 0}$ & 0.10 \\
\hline 10 & 0.03 & 0.02 & 0.01 & $\mathbf{0 . 0 3}$ & 0.03 & 0.03 & 0.02 & 0.03 \\
\hline 15 & 0.04 & 0.04 & 0.03 & 0.02 & 0.04 & 0.02 & 0.02 & 0.05 \\
\hline 20 & 0.00 & 0.01 & 0.01 & 0.00 & 0.01 & 0.01 & 0.00 & -0.00 \\
\hline 25 & -0.01 & 0.00 & 0.01 & -0.03 & -0.01 & -0.02 & -0.01 & -0.01 \\
\hline 30 & 0.02 & 0.02 & 0.03 & 0.02 & 0.01 & 0.01 & 0.02 & 0.02 \\
\hline
\end{tabular}

Total(-RH) model falls away from the one to one curve. Some of this drop in reliability is likely due to the small sample size of forecasts in this range. However, the reliability curve drops below the climatological skill (shown in the green line) for most forecast bins over $70 \%$. At other forecast lead times these dips in verification percentages for high probability forecasts are even more apparent. The Total(-RH) model is overpredicting in this range. The NL Total(-RH) appears to partially remedy this problem. For 5-day lead times, NL Total(-RH) predictions calling for $>60 \%$ chance of an active period has reliability that mostly falls above climatology. This improvement also appears for other lead times and for the Total versus NL Total (not shown). This can also be seen in the ROC values in Table 5. The hit-miss ratios for $>50 \%$ forecasts of an above average period in the Total(-RH) and NL Total(-RH) are nearly the same at 5-day lead times but are improved at all other lead times using NL Total(-RH) except 25-day leads. These improvements are mainly due to the reduction of high probability forecasts. NL Total(-RH) eliminates many false negative forecasts but also slightly reduces the number of hits. While the inclusion of nonlinear $\mathrm{MJO} /$ ENSO interactions did not appear to change the overall skill, it does improve the reliability (and therefore confidence) of the high probability forecasts. Reasons for this improvement will be covered in the discussion section.

While the NL Total(-RH) improves reliability, it comes at the expense of sharpness, or the ability of a model to produce forecasts that deviate from climatology as shown by the histograms (in gray). In general, by including fewer parameters in the logistic regression model (or combining several parameters into one such as for NL Total) there is less variability in the forecasts and less sharpness.

\section{f. Perfect predictors}

To test how skill can be improved, we compute the logistic regression model skill assuming either the shear parameters or
MJO PCs are forecasted perfectly (i.e., replacing Navy-ESPC forecasts with reanalysis data). As seen in Table 6, at five days, skill is lower using reanalysis values. This could be because the Navy-ESPC is overrepresenting the relationship between shear or the MJO and TC activity. ABY shear composites of NavyESPC 5-day forecasts have higher magnitudes than ABY shear constructed with reanalysis. Lee et al. (2018) also showed that some models overrepresent MJO-TC connections. Otherwise, perfect forecasts of the shear indices and MJO PCs lead to considerable improvements of probabilistic predictions for later lead times as would be expected. The greatest improvements and greatest skill at 10-25-day lead times occur for predictions with perfect shear forecasts. At 30 days perfect MJO and perfect shear forecasts produce roughly the same skill. Because the shear parameters reach their predictability limits at earlier lead times than the MJO, the predicted shear parameters may be unfairly degrading the total forecast with perfect MJO prediction. For comparison we also include the MJO_SST model with perfect MJO forecasts. While this model performs worse than the Total (MJO perfect) model for short lead times, the skill is improved for lead times of 15 days and longer. This model still does not perform better than the Total (shear perfect) model until 30-day lead times.

Of course, perfect forecasts are impossible, and improving forecasts are no small feat. The small spatial scale of the shear parameters may make them inherently less predictable, making improvements of the forecasted shear field on subseasonal scales more difficult, at least in comparison to improving MJO predictions.

\section{Physical mechanisms}

a. Nonlinear MJO-ENSO shear analysis

The linear combination of strong La Niña and MJO phases 8 and 1 would suggest high TC activity, but these cases in

TABLE 4. Names of the schemes of logistic regression models and the parameters that were used as inputs.

\begin{tabular}{ll}
\hline \hline \multicolumn{1}{c}{ Model name } & \multicolumn{1}{c}{ Parameters } \\
\hline Total & Bahamas shear, Caribbean shear, RH, MJO PC1, MJO PC2, Niño-3.4, MDR SST \\
MJO_SST & MJO PC1, MJO PC2, Niño-3.4, MDR SST \\
SST & Niño-3.4, MDR SST \\
NL Total & Bahamas shear, Caribbean shear, RH, MDR, Nonlinear MJO_ENSO ACE \\
Total(-RH) & Bahamas shear, Caribbean shear, MJO PC1, MJO PC2, Niño-3.4, MDR SST \\
Total MJO ACE & Bahamas shear, Caribbean shear, RH, MJO phase ACE, Niño-3.4, MDR SST \\
Total replace Niño-1+2 & Bahamas shear, Caribbean shear, RH, MJO PC1, MJO PC2, Niño-1+2, MDR SST \\
\hline
\end{tabular}



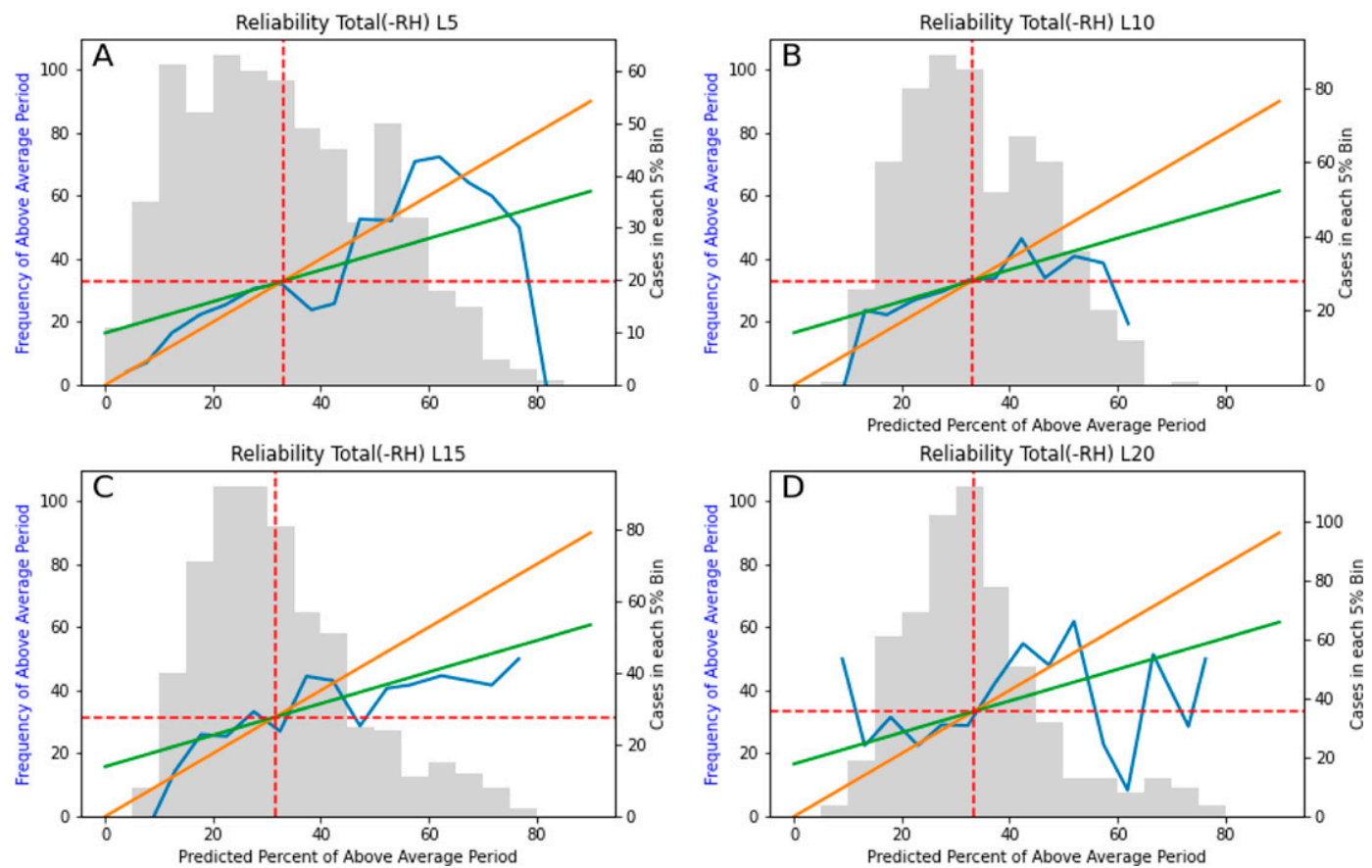

FIG. 3. Reliability diagrams for the Total(-RH) scheme for (a) 5-, (b) 10-, (c) 15-, and (d) 20-day forecasts. The blue line indicates the observed frequency of an above average $\mathrm{ACE}_{5}^{\prime}$ period for each $5 \%$ forecast bin. The orange line indicates a 1:1 ratio of predicted probability and observed frequency representing a perfect model. The green line indicates climatological skill. Vertical and horizontal dashed red lines indicate the climatological rate of active ACE' periods in the Atlantic. Gray bars indicate the number of forecasts that fall into each $5 \%$ bin.

observations show only slightly above average activity. The average shear anomaly during these cases (Fig. 5b) reveals a pattern that looks reminiscent of the ABY shear pattern, with high shear over the Bahamas and subtropical Atlantic and lower shear anomalies to the south. The key distinction is that this shear pattern is shifted south and east meaning that increased shear anomalies penetrate into the MDR. This shear anomaly appears to be primarily due to an increase in upper level (200 hPa) westerly winds (Fig. 5d). H20 hypothesized that combined La Niñas and favorable MJO phases may produce easterly shear impeding TC activity; however, this does not appear to be the case. For more moderate La Niñas this upper level wind anomaly is weaker and is shifted north lifting unfavorable shear patterns out of the MDR (Fig. 5a). The $850-\mathrm{hPa}$ winds are also less favorable for strong La Niñas and MJO phases 8 and 1 (Fig. 5f). In the Caribbean and western MDR, low level wind anomalies are westerly which would indicate slower trade winds and weaker shear favorable for TC activity. However, in the western MDR, these westerly wind anomalies are weaker during strong La Niñas than in weak La Niñas (Fig. 5e). Furthermore, in the eastern MDR, strong La Niñas are associated with low level easterly wind anomalies which is not seen for weaker La Niñas. All cases of strong La Niña and MJO phases 8 and 1 show a region of anomalously high shear dipping equatorward of $20^{\circ} \mathrm{N}$ over the Atlantic, although there is a lot of variability in shear anomalies between these cases.
For strong La Niñas the most active consecutive phases of the MJO are phases 3 and 4. Average shear anomalies under these conditions replicate the $\mathrm{ABY}$ shear signal indicating favorable conditions for TC activity (Fig. 6). For MJO phases 3 and 4, this shear pattern only becomes pronounced during strong La Niñas.

The MJO has been linked to Rossby wave-breaking (RWB) events which impact shear over the Atlantic (Li et al. 2018; Papin et al. 2020). The exact trajectory of these RWB events are modulated by ENSO (Lee et al. 2020b) and may lead to unfavorable shear conditions during typically favorable MJO and ENSO phases.

It is worth emphasizing that there are few cases for such strong La Niña events (years 1988, 1998, 2007, and 2010) and that longer analysis periods and/or modeling studies are needed to strengthen these results.

\section{b. Potential vorticity}

H20 suggested that the ABY shear signal was related to midlatitude weather. Many previous studies have shown midlatitude phenomena such as PV streamers have a complicated relationship with TC activity. These phenomena are linked to midlatitude RWB which cause increased shear and injections of dry stable air into the tropics although can aid in genesis in certain scenarios (Fitzpatrick et al. 1995; Zhang et al. 2017; Papin et al. 2020; Galarneau et al. 2015). To further examine the influence of RWB on subseasonal TC activity, we took an ABY composite of 200-hPa PV anomalies (Fig. 7) to serve as a proxy for the 350-K 

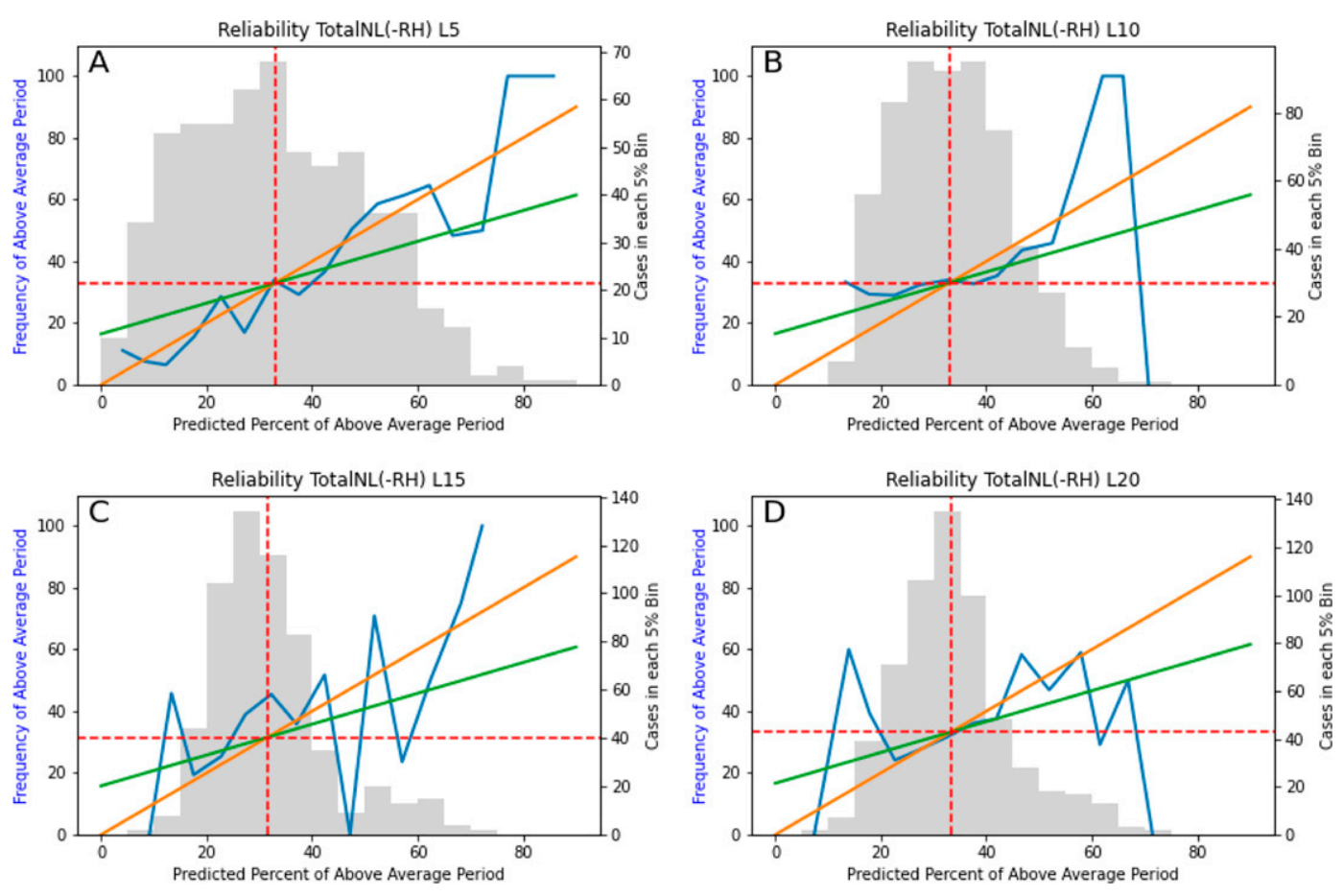

FIG. 4. As in Fig. 3, but for the Total NL(-RH) model.

isentrope as in Zavadoff and Kirtman (2020). Climatologically, PV streamers drape across the Atlantic extending from the north-east Atlantic to the north of the Caribbean (Papin et al. 2020). The ABY composite reveals reduced PV over climatological PV streamer areas. PV is increased over the east coast of the United States. The regions of anomalous shear in ABY coincide with the downstream region of PV anomalies. It appears that either a reduction of PV streamers or a poleward and westward shift in PV activity allows for reduced shear and increased TC activity. This highlights midlatitude dynamics as an important modulator of subseasonal variability of Atlantic TC activity and as a target for improved prediction.

\section{Summary and discussion}

In this study we constructed statistical-dynamical hybrid models for use in predicting subseasonal Atlantic TC activity. These models combined Navy-ESPC forecasts of atmospheric parameters and persistence forecasts of ocean SST parameters using multiple linear regression and logistic regression models. These models were used to compare the skill added by different predictors and allow us to test the utility of several potential new sources of predictability. The Niño-3.4 index, average MDR SST anomalies and the first two PCs of the MJO are used as the base predictors for the model (MJO_SST in the text).

This study is the first to assess the contribution of regional area average environmental parameters for subseasonal TC

TABLE 5. The ROC values for Total(-RH) and NL Total (-RH) schemes at increasing lead time in days.

\begin{tabular}{|c|c|c|c|c|c|}
\hline & Hit & False alarm & Miss & Correct negative & Hit/(hit + FA) \\
\hline \multicolumn{6}{|c|}{ Total(-RH) } \\
\hline 5 & 71 & 53 & 123 & 342 & 0.57 \\
\hline 10 & 28 & 41 & 167 & 353 & 0.41 \\
\hline 15 & 32 & 40 & 154 & 363 & 0.44 \\
\hline 20 & 25 & 36 & 171 & 357 & 0.41 \\
\hline 25 & 26 & 36 & 173 & 354 & 0.42 \\
\hline 30 & 16 & 35 & 164 & 374 & 0.31 \\
\hline \multicolumn{6}{|c|}{ NL Total (-RH) } \\
\hline 5 & 62 & 46 & 132 & 349 & 0.57 \\
\hline 10 & 23 & 22 & 172 & 372 & 0.51 \\
\hline 15 & 26 & 28 & 160 & 375 & 0.48 \\
\hline 20 & 23 & 30 & 173 & 363 & 0.43 \\
\hline 25 & 5 & 23 & 194 & 367 & 0.13 \\
\hline 30 & 11 & 23 & 169 & 386 & 0.32 \\
\hline
\end{tabular}


TABLE 6. Brier skill score of $\mathrm{ACE}_{5}^{\prime}$ forecasts using the logistic regression model forecast schemes at increasing lead times in days. The average daily climatology or zero $\mathrm{ACE}_{5}^{\prime}$ is used as the baseline prediction. Bolded values indicate that the model is the best performing or competitive with the best performing model for that lead time.

\begin{tabular}{rrccc}
\hline \hline BSS & Total & Total (observed shear) & Total (observed MJO) & MJO_SST (observed MJO) \\
\hline 5 & $\mathbf{0 . 1 0}$ & 0.07 & 0.09 & 0.01 \\
10 & 0.03 & $\mathbf{0 . 0 7}$ & 0.02 & 0.02 \\
15 & 0.04 & $\mathbf{0 . 0 9}$ & 0.03 & 0.04 \\
20 & 0.00 & $\mathbf{0 . 0 6}$ & 0.03 & 0.04 \\
25 & -0.01 & $\mathbf{0 . 0 4}$ & 0.01 & 0.02 \\
30 & 0.02 & $\mathbf{0 . 0 5}$ & $\mathbf{0 . 0 5}$ & $\mathbf{0 . 0 5}$ \\
\hline
\end{tabular}

prediction. Two shear parameters are constructed based on the ABY shear pattern found in $\mathrm{H} 20$. One parameter capturing a region of above average shear over the Bahamas and Bermuda and the other a region of below average shear over the eastern Caribbean that were found in association with subseasonal Atlantic TC activity. By adding Navy-ESPC forecasted values of these shear predictors to the base predictors in the logistic regression model, skill was improved at 5- and 10-day lead times. However, at 15-day lead times the model performs better without the inclusion of the shear predictors.

The skill of the Total model (which incorporates shear predictors) is comparable to previous studies and crucially appears to improve upon skill around 10-day lead times extending predictability into the subseasonal timeframe. We set a high bar for our model by forecasting ACE anomalies as opposed to discrete values of ACE or TC genesis used in Leroy and Wheeler (2008), Henderson and Maloney (2013). Our BSS values at early lead-times are roughly equivalent to the BSS values found in these studies.

Subseasonal TC forecasts in Lee et al. (2020a) use ACE anomalies allowing us to directly compare our skill with the dynamical models used in their study. The BSS of our Total model in predicting ACE anomalies is higher than the BSS from uncalibrated TC forecasts in the S2S models for nearly
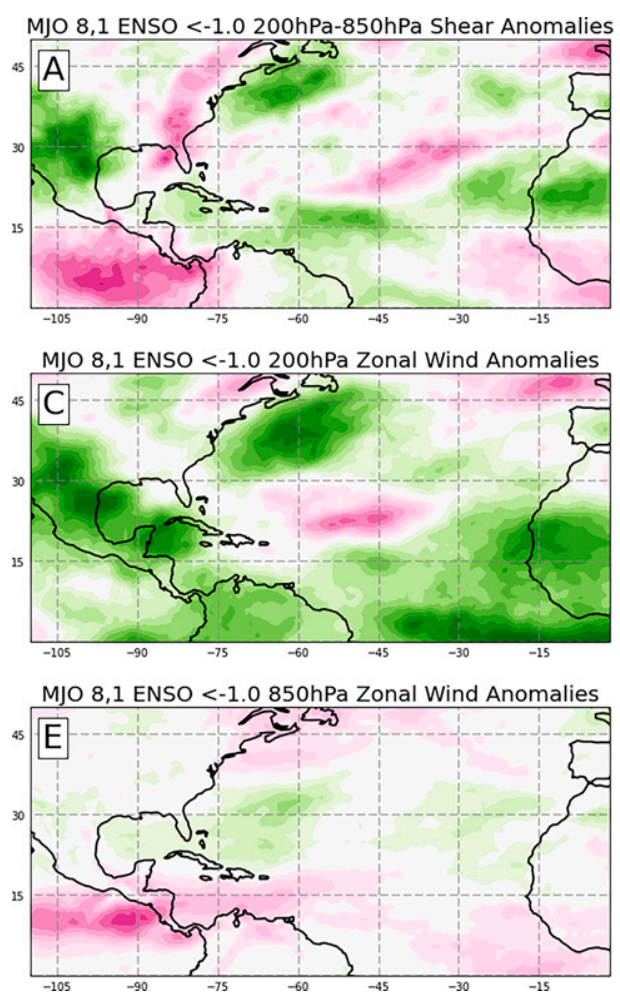
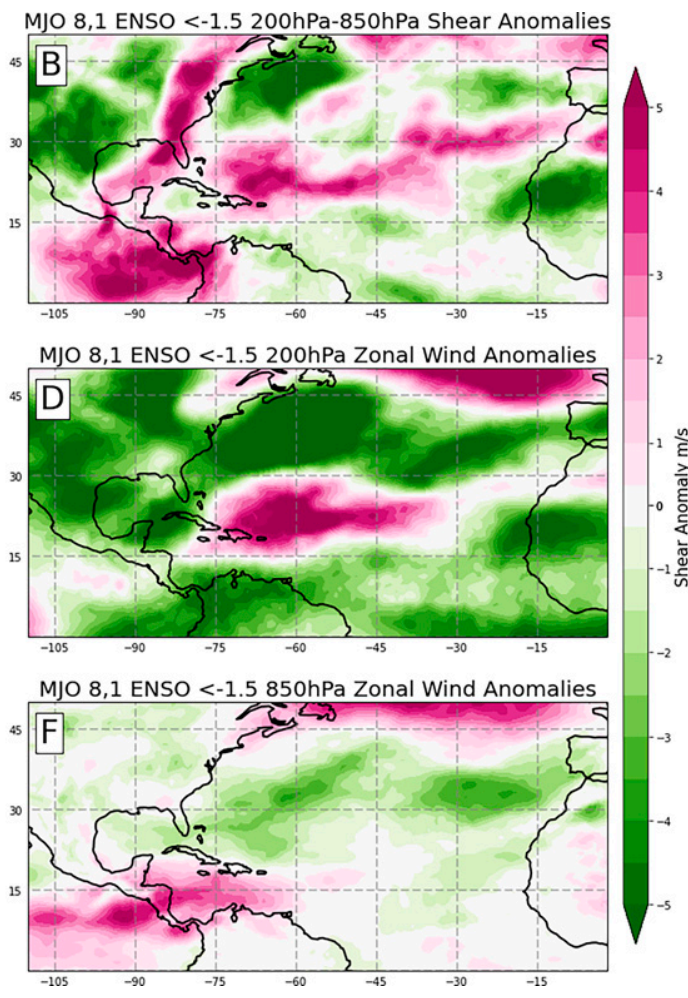

FIG. 5. ERA5 anomalous values $\left(\mathrm{m} \mathrm{s}^{-1}\right.$ ) of (a) 200-850-hPa wind shear during MJO phases 8 and 1 for Niño-3.4 SST values less than $-1.0^{\circ} \mathrm{C}$, (b) 200-850-hPa wind shear during MJO phases 8 and 1 for Niño-3.4 SST values less than $-1.5^{\circ} \mathrm{C}$, (c) $200-\mathrm{hPa}$ zonal wind during MJO phases 8 and 1 for Niño-3.4 SST values less than $-1.0^{\circ} \mathrm{C}$, (d) 200-hPa zonal wind during MJO phases 8 and 1 for Niño-3.4 SST values less than $-1.5^{\circ} \mathrm{C}$, (e) 850 -hPa zonal wind during MJO phases 8 and 1 for Niño-3.4 SST values less than $-1.0^{\circ} \mathrm{C}$, and (f) $850-\mathrm{hPa}$ zonal wind during MJO phases 8 and 1 for Niño-3.4 SST values less than $-1.5^{\circ} \mathrm{C}$. 


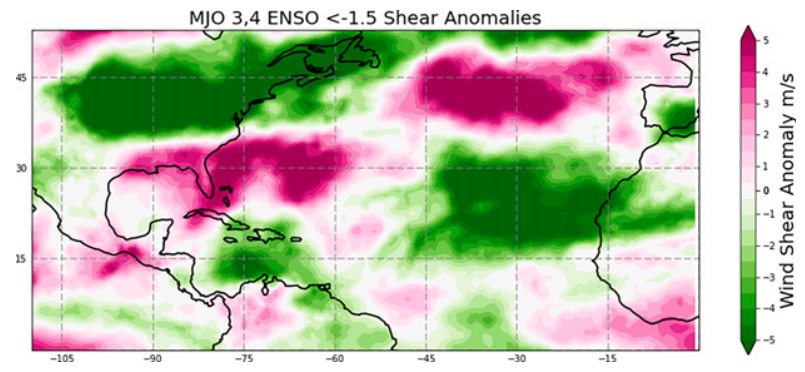

FIG. 6. As in Fig. 5b, but for MJO phases 3 and 4 (and Niño-3.4 SST values less than $-1.5^{\circ} \mathrm{C}$ ).

all models and for nearly all lead times. Notably, the BSS of explicit TC forecasts by the Navy-ESPC in Lee et al. (2020a) is much lower than the BSS found in our study using NavyESPC forecasts of shear parameters in a statistical-dynamical hybrid model for all lead times. This suggests that the forecasts of environmental parameters, particularly shear, are useful in the subseasonal range. Vitart et al. (2010) obtained skill from calibrated dynamical model forecast of TCs that is higher than our statistical-dynamical hybrid, although comparisons with this study are complicated by differing basins and base climatologies.

Some of the predictability of the shear parameters can be attributed to the MJO which is responsible for lower shear in the Caribbean and MDR. However, H20 showed another phenomena was likely contributing to the dipole shear pattern hinting that another physical mechanism could potentially be used to provide predictability. We suggest here, this mechanism is PV streamers. ABY composites of PV anomalies show low PV anomalies occur around Hispaniola trailing to the ENE around the region of climatological PV streamers and high PV anomalies occur over the east coast of the United States. PV streamers are typically associated with reduced shear upstream and increased shear downstream and to the south. These PV anomalies in the ABY composite align with the ABY composite of shear anomalies. These results are consistent in showing that either the absence or northward displacement of PV streamers are a key factor in determining subseasonal variability of TC activity in the Atlantic.

Other parameters tested were not as useful in improving subseasonal predictive skill as vertical wind shear. Central Atlantic

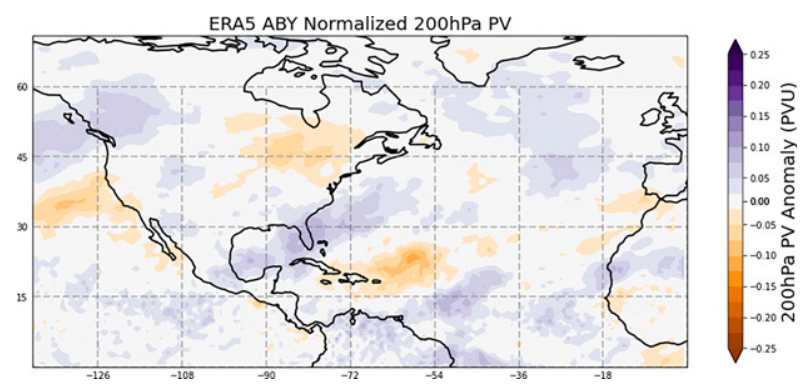

FIG. 7. ABY composites of the top third of subseasonal ACE' events in the Atlantic during ASO 1979-2019 of ERA5 values of normalized 200-hPa potential vorticity.
RH and basin-wide RH were tested as a predictors. In the Total model, the inclusion of $\mathrm{RH}$ as a predictor slightly degraded the forecast skill at nearly all lead times. This is surprising considering $\mathrm{RH}$, besides impacting TCs directly, is linked to many phenomena that modulate TC activity on a variety of scales such as ENSO, MJO, the Saharan air layer, and PV streamers among others (Camargo et al. 2007, 2009; Shu and Wu 2009; Zhang et al. 2017). However, considering that ABY composites show that the majority of the subseasonal RH signal comes from TCs themselves and, thus, is not representative of the environment and that $\mathrm{RH}$ predictors have weak and inconsistent correlations with $\mathrm{ACE}_{5}^{\prime}$, it is not unforeseen that RH does not contribute to the skill of the model. Midlevel RH could be a poor measure of moisture; cool stable air, like that associated with PV streamers, is not expressed well in $\mathrm{RH}$ fields.

Incorporating nonlinear $\mathrm{MJO} / \mathrm{ENSO}$ interactions by calculating average out of sample $\mathrm{ACE}_{5}^{\prime}$ anomalies in bins in $\mathrm{MJO} /$ ENSO phase space generally resulted in the model having similar or slightly lower BSS. However, the nonlinear component did help improve the reliability of the model at most lead times. The linear combination of MJO and ENSO resulted in a (relatively) large number of forecasts that predicted a likely ( $>50 \%$ ) chance for above average TC activity; however, these verified less than $50 \%$ of the time. As $\mathrm{H} 20$ found that the combination of typically favorable MJO phases and ENSO phases resulted in near average TC activity, the overconfidence of the linear model was expected. By using the nonlinear $\mathrm{MJO} /$ ENSO predictor, many false alarms were removed, improving the confidence in high probability forecasts. However, we found this nonlinear connection is not as strong as that found in $\mathrm{H} 20$ and may be dependent on the metric used to define the MJO. Given the relatively few cases of simultaneous strong La Niñas and MJO phases 8 and 1, there is large variability associated with out of sample $\mathrm{ACE}_{5}^{\prime}$ values.

Shear composites of combined MJO/ENSO phases suggest a real physical mechanism guiding a nonlinear MJO/ENSO impact on Atlantic TC activity. MJO phases 3 and 4 are the most active MJO phases during strong La Niñas, and composites of shear anomalies during these periods exhibit a pattern that is similar to the ABY shear signal. Shear anomalies during MJO phases 8 and 1 during strong La Niñas exhibit regions of strong shear anomalies farther south than in phases 3 and 4 impeding on the MDR. H20 hypothesized that the combination of favorable MJO and ENSO phases could reverse the climatological westerly shear and create an unfavorable easterly shear. This is not the case as high shear anomalies during MJO phases 8 and 1 and strong La Niñas are associated with enhanced upper level westerlies. While there is large variability in shear regions between these cases, all exhibit a region of increased shear caused by anomalous upper level westerlies over the Caribbean or MDR. Nonlinear MJO/ENSO dynamics may be modulating Atlantic TC activity through RWB events. Previous literature supports this; Lin and Derome (2004) noted that tropical Pacific forcing during winter in La Niña states yield a stronger response in the North Atlantic than in El Niños. Perhaps during summer this enhanced response during very strong La Niñas manifests as stronger, more southerly shear. 
To test how forecasts could be improved, Navy-ESPC forecasted shear parameters and MJO PCs were individually replaced with observed values, simulating perfect forecasts. For lead times from 10 to 25 days, having a perfect shear forecast produces the highest skill, whereas at 30-day lead times perfect MJO forecasts result in the most skillful predictions. These results suggest that the easiest way to improve subseasonal TC forecasts is through accurate representation of shear which may be done by better resolving midlatitude features. While generally predictability of the midlatitudes is low, blocking events may create relatively stable regimes that allow forecasts of opportunity.

We demonstrated that the statistical-dynamical model offers a simple method to create skillful subseasonal TC forecasts. Our method could be improved upon in many relatively easy ways. The use of ensembles is one method that is key to improving skill in the subseasonal timeframe (Pegion and Sardeshmukh 2011). The operational Navy-ESPC has a 16member ensemble and a multimodel ensemble can be created using other models in the SUBX project which would improve forecasts of the shear and MJO parameters. Additional precision could be added to our method by including forecasted SST values from a dynamical model. Model shear anomaly forecasts could be made relative to both the seasonal cycle and model lead time to give the most accurate results. Environmental parameters could be optimized by including a metric to represent $\mathrm{PV}$ streamer activity or optimization of the regions used to define the shear (or even SST) parameters.

The main finding of this work is that incorporating NavyESPC shear forecasts into a statistical-dynamical hybrid model improves predictions of subseasonal TC activity for lead times of 5-10 days and preforms better than explicit TC forecasts from weather models. We also find that while improvements to MJO forecasts would increase TC forecast skill, we find that for 10-25-day lead times there is more skill to be gained from improved forecasts of shear parameters and that future modeling efforts should work on correcting shear biases. The shear parameters used in this study are linked to PV streamers suggesting that RWB events can provide subseasonal predictability and should be another target for model verification.

While these results are specific to TC activity in the Atlantic, this work has much broader implications for the future of subseasonal forecasting. The ABY method developed in $\mathrm{H} 20$ finds patterns of environmental conditions associated with subseasonal variability and we have shown these can be applied to forecasting to extend predictability into the subseasonal timeframe. This approach would be particularly useful for multimodel ensemble prediction of TCs (or other complex phenomena) by accessing skill from models that are unable to resolve difficult small-scale features. This work also shows the utility of statistical dynamical hybrid models as especially applicable in the subseasonal range.

Acknowledgments. Kurt Hansen gratefully acknowledges the receipt of a University of Miami Graduate Fellowship. I would like to thank the reviewers and the editor for their helpful comments that improved the manuscript and the Naval Research Enterprise Intern Program for facilitating an internship with the Naval Research Lab. Matthew Janiga acknowledges the support of the Chief of Naval Research through the NRL Base Program, Extended-Range Tropical Cyclone Prediction 6.2 (PE 62435N). The generation of the Navy-ESPC forecasts was supported in part by a grant of HPC time from the Department of Defense Major Shared Resource Centers, Stennis Space Center, MS. Discussions with David Nolan and Kathleen Pegion were helpful in sharpening the study.

Data availability statement. The IBTrACS dataset used to calculate TC metrics can be found at https://www.ncdc.noaa. gov/ibtracs/. The ERA5 dataset used to calcualte ABY and shear composites can be found at "https://cds.climate. copernicus.eu/\#!/search?text=ERA5\&type=dataset." NavyESPC reforecast data from the SUBX archive can be found at https://iridl.ldeo.columbia.edu/SOURCES/.Models/.SubX/. NRL/.NESM/.hindcast/.

\section{REFERENCES}

Barton, N., and Coauthors, 2021: The Navy's Earth System Prediction Capability: A new global coupled atmosphere-oceansea ice prediction system designed for daily to subseasonal forecasting. Earth Space Sci., 8, e2020EA001199, https://doi. org/10.1029/2020EA001199.

Belanger, J. I., J. A. Curry, and P. J. Webster, 2010: Predictability of North Atlantic tropical cyclone activity on intraseasonal time scales. Mon. Wea. Rev., 138, 4362-4374, https://doi.org/ 10.1175/2010MWR3460.1.

Camargo, S. J., 2013: Global and regional aspects of tropical cyclone activity in the CMIP5 models. J. Climate, 26, 98809902, https://doi.org/10.1175/JCLI-D-12-00549.1.

— , K. A. Emanuel, and A. H. Sobel, 2007: Use of a genesis potential index to diagnose ENSO effects on tropical cyclone genesis. J. Climate, 20, 4819-4834, https://doi.org/10.1175/ JCLI4282.1.

—, M. C. Wheeler, and A. H. Sobel, 2009: Diagnosis of the MJO modulation of tropical cyclogenesis using an empirical index. J. Atmos. Sci., 66, 3061-3074, https://doi.org/10.1175/ 2009JAS3101.1.

Camp, J., and Coauthors, 2018: Skilful multiweek tropical cyclone prediction in ACCESS-S1 and the role of the MJO. Quart. J. Roy. Meteor. Soc., 144, 1337-1351, https://doi.org/10.1002/qj. 3260.

Carman, J. C., and Coauthors, 2017: The National Earth System Prediction Capability: Coordinating the giant. Bull. Amer. Meteor. Soc., 98, 239-252, https://doi.org/10.1175/BAMS-D16-0002.1.

de Boyer Montégut, C., G. Madec, A. S. Fischer, A. Lazar, and D. Iudicone, 2004: Mixed layer depth over the global ocean: An examination of profile data and a profile-based climatology. J. Geophys. Res., 109, C12003, https://doi.org/10.1029/ 2004JC002378.

DeMaria, M., 1996: The effect of vertical shear on tropical cyclone intensity change. J. Atmos. Sci., 53, 2076-2088, https://doi.org/ 10.1175/1520-0469(1996)053<2076:TEOVSO>2.0.CO;2.

Elsberry, R. L., M. S. Jordan, and F. Vitart, 2010: Predictability of tropical cyclone events on intraseasonal timescales with the 
ECMWF monthly forecast model. Asia-Pac. J. Atmos. Sci., 46, 135-153, https://doi.org/10.1007/s13143-010-0013-4.

Fitzpatrick, P. J., J. A. Knaff, C. W. Landsea, and S. V. Finley, 1995: Documentation of a systematic bias in the aviation model's forecast of the Atlantic tropical upper-tropospheric trough: Implications for tropical cyclone forecasting. Wea. Forecasting, 10, 433-446, https://doi.org/10.1175/1520-0434(1995)010<0433: DOASBI $>2.0 . \mathrm{CO} ; 2$.

Galarneau, T. J., R. McTaggart-Cowan, L. F. Bosart, and C. A. Davis, 2015: Development of North Atlantic tropical disturbances near upper-level potential vorticity streamers. J. Atmos. Sci., 72, 572-597, https://doi.org/10.1175/JAS-D-14-0106.1.

Gray, W. M., 1979: Hurricanes: Their formation, structure and likely role in the tropical circulation. Meteorology over the Tropical Oceans, B. Shaw, Ed., Royal Meteorological Society, 155-218.

— 1984: Atlantic seasonal hurricane frequency. Part I: El Niño and $30 \mathrm{mb}$ Quasi Biennial Oscillation influences. Mon. Wea. Rev., 112, 1649-1668, https://doi.org/10.1175/ 1520-0493(1984)112<1649:ASHFPI > 2.0.CO;2.

Hansen, K. A., S. J. Majumdar, and B. P. Kirtman, 2020: Identifying subseasonal variability relevant to Atlantic tropical cyclone activity. Wea. Forecasting, 35, 2001-2024, https://doi. org/10.1175/WAF-D-19-0260.1.

Henderson, S. A., and E. D. Maloney, 2013: An intraseasonal prediction model of Atlantic and east Pacific tropical cyclone genesis. Mon. Wea. Rev., 141, 1925-1942, https://doi.org/10. 1175/MWR-D-12-00268.1.

Hersbach, H., and Coauthors, 2020: The ERA5 global reanalysis. Quart. J. Roy. Meteor. Soc., 146, 1999-2049, https://doi.org/10. 1002/qj.3803.

Hsu, W., and A. H. Murphy, 1986: The attributes diagram a geometrical framework for assessing the quality of probability forecasts. Int. J. Forecasting, 2, 285-293, https://doi.org/10. 1016/0169-2070(86)90048-8.

Janiga, M. A., C. J. Schreck, J. A. Ridout, M. Flatau, N. P. Barton, E. J. Metzger, and C. A. Reynolds, 2018: Subseasonal forecasts of convectively coupled equatorial waves and the MJO: Activity and predictive skill. Mon. Wea. Rev., 146, 2337-2360, https://doi.org/10.1175/MWR-D-17-0261.1.

Jones, C., D. E. Waliser, K. M. Lau, and W. Stern, 2004: Global occurrences of extreme precipitation and the Madden-Julian oscillation: Observations and predictability. J. Climate, 17, 4575-4589, https://doi.org/10.1175/3238.1.

Kiladis, G. N., J. Dias, K. H. Straub, M. C. Wheeler, S. N. Tulich, K. Kikuchi, K. M. Weickmann, and M. J. Ventrice, 2014: A comparison of OLR and circulation-based indices for tracking the MJO. Mon. Wea. Rev., 142, 1697-1715, https://doi.org/ 10.1175/MWR-D-13-00301.1.

Kim, H., F. Vitart, and D. E. Waliser, 2018: Prediction of the Madden-Julian Oscillation: A review. J. Climate, 31, 9425-9443, https://doi.org/10.1175/JCLI-D-18-0210.1.

Klotzbach, P. J., 2007: Revised prediction of seasonal Atlantic basin tropical cyclone activity from 1 August. Wea. Forecasting, 22, 937-949, https://doi.org/10.1175/WAF1045.1.

— , and E. C. J. Oliver, 2015: Modulation of Atlantic basin tropical cyclone activity by the Madden-Julian oscillation (MJO) from 1905 to 2011. J. Climate, 28, 204-217, https://doi.org/10. 1175/JCLI-D-14-00509.1.

Knapp, K. R., M. C. Kruk, D. H. Levinson, H. J. Diamond, and C. J. Neumann, 2010: The International Best Track Archive for Climate Stewardship (IBTrACS). Bull. Amer. Meteor. Soc., 91, 363-376, https://doi.org/10.1175/2009BAMS2755.1.
Knutson, T. R., K. M. Weickmann, and J. E. Kutzbach, 1986: Global-scale intraseasonal oscillations of outgoing longwave radiation and $250 \mathrm{mb}$ zonal wind during Northern Hemisphere summer. Mon. Wea. Rev., 114, 605-623, https://doi. org/10.1175/1520-0493(1986)114<0605:GSIOOO>2.0.CO;2.

Landsea, C. W., and J. L. Franklin, 2013: Atlantic hurricane database uncertainty and presentation of a new database format. Mon. Wea. Rev., 141, 3576-3592, https://doi.org/10.1175/MWRD-12-00254.1.

Lee, C.-Y., S. J. Camargo, F. Vitart, A. H. Sobel, and M. K. Tippett, 2018: Subseasonal tropical cyclone genesis prediction and MJO in the S2S dataset. Wea. Forecasting, 33, 967-988, https://doi.org/10.1175/WAF-D-17-0165.1.

,,-- F. Vitart, A. H. Sobel, J. Camp, S. Wang, M. K. Tippett, and Q. Yang, 2020a: Subseasonal predictions of tropical cyclone occurrence and ace in the S2S dataset. Wea. Forecasting, 35, 921-938, https://doi.org/10.1175/WAF-D-19-0217.1.

Lee, J. C. K., R. W. Lee, S. J. Woolnough, and L. J. Boxall, 2020b: The links between the Madden-Julian Oscillation and European weather regimes. Theor. Appl. Climatol., 141, 567-586, https://doi.org/10.1007/s00704-020-03223-2.

Leroy, A., and M. C. Wheeler, 2008: Statistical prediction of weekly tropical cyclone activity in the Southern Hemisphere. Mon. Wea. Rev., 136, 3637-3654, https://doi.org/10.1175/ 2008MWR2426.1.

Li, W., Z. Wang, G. Zhang, M. S. Peng, S. G. Benjamin, and M. Zhao, 2018: Subseasonal variability of Rossby wave breaking and impacts on tropical cyclones during the North Atlantic warm season. J. Climate, 31, 9679-9695, https://doi.org/10. 1175/JCLI-D-17-0880.1.

Lin, H., and J. Derome, 2004: Nonlinearity of the extratropical response to tropical forcing. J. Climate, 17, 2597-2608, https:// doi.org/10.1175/1520-0442(2004)017<2597:NOTERT>2.0.CO;2.

Moon, Y., D. Kim, S. J. Camargo, A. A. Wing, K. A. Reed, M. F. Wehner, and M. Zhao, 2020: A new method to construct a horizontal resolution-dependent wind speed adjustment factor for tropical cyclones in global climate model simulations. Geophys. Res. Lett., 47, e2020GL087528, https:// doi.org/10.1029/2020GL087528.

Papin, P. P., L. F. Bosart, and R. D. Torn, 2020: A feature-based approach to classifying summertime potential vorticity streamers linked to Rossby wave breaking in the North Atlantic basin. $J$. Climate, 33, 5953-5969, https://doi.org/10.1175/JCLI-D-19-0812.1.

Pegion, K., and P. D. Sardeshmukh, 2011: Prospects for improving subseasonal predictions. Mon. Wea. Rev., 139, 3648-3666, https://doi.org/10.1175/MWR-D-11-00004.1.

— , and Coauthors, 2019: The subseasonal experiment (SubX): A multimodel subseasonal prediction experiment. Bull. Amer. Meteor. Soc., 100, 2043-2060, https://doi.org/10.1175/ BAMS-D-18-0270.1.

Qian, Y., P.-C. Hsu, H. Murakami, B. Xiang, and L. You, 2020: A hybrid dynamical statistical model for advancing subseasonal tropical cyclone prediction over the western North Pacific. Geophys. Res. Lett., 47, e2020GL090095, https://doi.org/10.1029/ 2020GL090095.

Russell, J. O., A. Aiyyer, J. D. White, and W. Hannah, 2017: Revisiting the connection between African easterly waves and Atlantic tropical cyclogenesis. Geophys. Res. Lett., 44, 587-595, https://doi.org/10.1002/2016GL071236.

Shu, S., and L. Wu, 2009: Analysis of the influence of Saharan air layer on tropical cyclone intensity using AIRS/Aqua data. Geophys. Res. Lett., 36, L09809, https://doi.org/10.1029/ 2009 GL037634. 
Vitart, F., A. Leroy, and M. C. Wheeler, 2010: A comparison of dynamical and statistical predictions of weekly tropical cyclone activity in the Southern Hemisphere. Mon. Wea. Rev., 138, 3671-3682, https://doi.org/10.1175/2010MWR3343.1.

—, A. W. Robertson, and D. L. Anderson, 2012: Sub-seasonal to seasonal prediction project: Bridging the gap between weather and climate. WMO Bull., 61, 23-28.

Wilks, D. S., 2011: Statistical Methods in the Atmospheric Sciences. 3rd ed. International Geophysics Series, Vol. 100, Academic Press, $704 \mathrm{pp}$.
Zavadoff, B. L., and B. P. Kirtman, 2020: Dynamic and thermodynamic modulators of European atmospheric rivers. $J$. Climate, 33, 4167-4185, https://doi.org/10.1175/JCLI-D-190601.1.

Zhang, C., 2005: Madden-Julian Oscillation. Rev. Geophys., 43, RG2003, https://doi.org/10.1029/2004RG000158.

Zhang, G., Z. Wang, M. S. Peng, and G. Magnusdottir, 2017: Characteristics and impacts of extratropical Rossby wave breaking during the Atlantic hurricane season. J. Climate, 30, 2363-2379, https://doi.org/10.1175/JCLI-D-16-0425.1. 